\title{
How Many Visitors Should there Be in the City? The Case of Rome
}

\author{
Valentina Feliziani \\ Social Science Department, Political Social and Communication Faculty \\ Sapienza University of Rome \\ Piazzale Aldo Moro 5, 00185, Rome, Italy \\ E-mail: valentina.feliziani@uniroma1.it
}

Marco Miarelli

Freelance Consultant

Via dei Tigli 14

02100 Rieti, Italy

E-mail:marco.miarelli@gmail.com

$\begin{array}{lrr}\text { Received: April 6, } 2012 & \text { Accepted: May 18, } 2012 & \text { Published: June 1, } 2012 \\ \text { doi:10.5539/res.v4n2p179 } & \text { URL: http://dx.doi.org/10.5539/res.v4n2p179 }\end{array}$

\begin{abstract}
This paper measures the carrying capacity of Rome. The model used for this analysis is a mathematical model of constrained optimization and linear programming. The function to maximize is the function of income generated by visitors to Rome based on physical constraints such as the number of parking spaces, beds, jobs in catering and social ties as determined through the estimation of two utility functions: residents who earn a living from tourism and residents who do not. To this end, a parameter whose variation indicates the greater or lesser utility of two social groups needed to be included in the constraints. The results of empirical analysis are as follows: the optimal number of tourist hotels and other accommodation is higher than the actual number of city users. In addition, the daily optimal revenue is more than the actual figure, representing a loss of earnings for the city. This analysis also shows the tightest constraints which are those that economic policy should focus on.
\end{abstract}

Keywords: Urban tourism, Carrying capacity

\section{Introduction}

The aim of this paper is to calculate the carrying capacity of the city of Rome. The carrying capacity as quoted by Fisher A.C. and Krutilla J.V., 1972, is the sum of the physical (Joardar S.D., 1998, Deyak T. and Smith V.K. 1978), economic (Duffield B.S., 1982, Dwyer L. et al. R.,2004) and social (Mbaiwa J.E., 2005, Snaith T. and Haley A., 1999, Van de Borg J et al. 1996, Doxey G.V., 1975) carrying capacity.

The linear programming model to maximize constraints defined by Canestrelli - Costa (1991) for the city of Venice was used to estimate the carrying capacity of Rome. Although the model was developed in the 1990s, it was chosen because it is the only one that estimates different load capacities and condenses them into one measure, the carrying capacity. In this respect, it is important to specify that the aim of the analysis is to estimate the carrying capacity of the city, as previously stated; a valuation of this type includes both tourist flows and the fluctuating population, something that is extremely important in Rome. Indeed, since Rome is a metropolitan and also a capital city, it exerts a magnetic force on people who live in the hinterland and commute to work in the city (Terence W.J., 1978, Guitiérrez-i-Puigarnau E. and van Ommeren J.N., 2010). The following paragraphs include a literature review and a hypothesis of analysis, an empirical analysis of the city of Rome and the main results. The analysis produces important results that can be used to implement policy changes to urban economics not only with regard to growth, but more importantly, urban development. 


\section{The Literature Review}

Although there is a large body of literature on sustainable tourism, it is limited to examining rural and coastal rather than urban areas (Debbage 1990, Holder 1991, Knowles and Curtis 1999, Prideaux 2000). Little attention has been paid to tourism in cities of art: it was not until the 1990s that a part of the literature began to examine the sustainability of urban tourism and cities of art in particular (Ashworth 1994, Van der Borg 1991 and Cazes and Potier, 1996). Cities of art were first defined by Ashworth and Tunbridge (1990). A city of art is, above all, a heritage city where the ancient, historical and cultural part dominates to the point that it is supported by appropriate regional policies. This part is also linked to other, more modern parts. Law (1993) and Van de Berg, Van de Borg and Van de Meer (1995) were the first to deal with overcoming the minimum limit to sustainability that Costa and Van de Borg (1992) went on to call the "carrying capacity". As part of the "Visitor flows in cities of art" research programme that began in 1990 and was published in 1996, Van der Borg J., Costa P. and Gotti G., working on behalf of CISET (the International Centre of Studies on the Tourism Economy) and UNESCO, studied the impact of tourist flows on various medium-sized cities of art in Europe (Note1) and provided guidelines on how to intervene effectively to control tourist flows. In 1990, Martin and Uysal examined the relationship between carrying capacity and the tourism life cycle in a destination. However, it was not until 1991 that the first quantitative study on measuring the carrying capacity was performed by Canestrelli E. and Costa P. who proposed the linear programming method to quantify the carrying capacity of the city of Venice. Unlike other models which are not systemic and analyse individual aspects separately ignoring others, the Canestrelli Costa model (1991) used in this study takes into account the fact that balances are achieved at various levels in tourist destinations: on market goods and services and on non-market goods and services, on individuals, tourists and daily users who demand, on tourist operators, public and private who supply and on the host community that experiences the positive and negative effects of the tourist destination. This means that the critical threshold must be assessed by taking into account all the constraints that characterize the carrying capacity: the physical constraint (Archer, 1996), the economic/financial constraint which is one of the most important (Prud'homme, 1986) and the social constraint (Getz, 1994, Gilbert D., Clark M., 1997, Snaith T., Haley A., 1999), which has received little attention in the literature (Bimonte S., Punzo L.F., 2005). To use the model, we must consider two hypotheses, one related to the phenomenon of commuting and the other, the multidimensional nature of Rome.

The phenomenon of commuting is particularly significant in Rome and we should not overlook the fact that data on tourist trips also includes a number of commuters. In this analysis, commuters and excursionist tourists are therefore considered city users, without differentiating between them. This estimate does not weaken the quality of the analysis if we consider that the objective of this work is to evaluate the city's carrying capacity and estimate an optimal mix of categories, irrespective of their motivation. We should also consider that average expenditure also includes commuter expenditure in addition to that of day-trippers in the function to be maximized: for this reason, the income to be maximized is not only made up of income from tourism, but also income from visitors to Rome.

The second hypothesis concerns the multidimensional nature of Rome. Like Venice, a city of art but also a port, we assume that Rome is a city of art but that it also has other functions, i.e., it is a city that focuses on the tertiary sector and is also the capital of Italy. We can therefore argue that citizens do not share the same view of tourism and are not all in favour of or against tourism. Consequently, there may be social conflict between those who earn a living from tourism and those who do not. Some sort of social carrying capacity can therefore be identified.

\section{Analysis and Methodology}

Linear programming techniques can be used to identify the different values of $\theta$ and identify the optimal mix of visitors that guarantees the maximum daily revenue for each one of them; this revenue is compatible with the imposed constraints consisting of the load capacity of each subset and the differences in behaviour of the different subjects with regard to these subsets. Moreover, Soleimani and Jahanshahloo (2007) deal with linear programming models with variable parameters, as in this case.

The objective function to be maximized is the following:

$$
\operatorname{Max}(\mathrm{Z})=\operatorname{Max}\left(c_{1} \mathrm{TH}+c_{2} T N H+c_{3} \mathrm{CU}\right)
$$

where:

$\mathrm{Z}=$ income from visitors to Rome;

$\mathrm{C}_{1}, \mathrm{C}_{2}, \mathrm{C}_{3}=$ average daily expenditure per head of each category considered;

$\mathrm{TH}=$ tourists staying in hotels; 
$T N H=$ tourists not staying in hotels;

$C U=$ city users (the daily number of city users including day-trippers and commuters).

As in Venice, since a priori information on the distribution of expenditure was not available, an equal weight ( 0.5 of probability) was given to the minimum and maximum values and the average assumed to be a proxy for expenditure for each category of visitors.

The value of each function also depends on other constraints:

$$
a_{i} x<b_{i}+\theta p_{i} \quad I=1,2 \ldots, 7
$$

where:

$x=$ tourists staying in hotels, tourists not staying in hotels, city users,

$$
x>0,0<\theta<1
$$

$\mathrm{a}_{\mathrm{i}}=$ coefficient vector that measures the level of daily use of the $\mathrm{n}$-th service by each category of visitors;

$b_{i}=$ the optimal capacity level of the $n$-th subsystem based on the section of the population not dependent on tourism; this level was estimated as the maximum net capacity of the share of visitor use. The theory in fact is that those who do not depend on tourism maximize their utility function when the subsystems are only utilized by residents.

$b_{i}+p_{i}=$ optimal level of utilization of the same subsystem according to tourist entrepreneurs; in theory, this level is equal to the maximum capacity of the considered subsystem; $\theta=$ lies between zero and one; the degree of violation of $b_{i}$ towards the insuperable $b_{i}+p_{i}$ limit which is the maximum level of pressure that can be tolerated by the $n$-th subsystem.

The data utilized in this analysis refers to the Municipality of Rome in 2006. Numerous different statistical data sources have been used according to the variables in the model. For this reason, we have chosen to introduce them gradually in the rest of the text to avoid making a list.

The estimates on the function to be maximized relate to average per capita expenditure since the scope of the analysis is to find the optimum number of hotel tourists, non-hotel tourists and daily city users: these variables will be determined by the conditioned optimization model solution.

The average per capita expenditure per day of the hotel and non-hotel tourists comes from the Ente Bilaterale Turismo Locale (EBTL) for 2006 for the Municipality of Rome and is equal to 297,000 US dollars for hotel tourists and 247,000 US dollars for non-hotel tourists (this data is based on presences). The estimate of the average expenditure of city users, not available from the EBTL source, was based on Coses data for 2006, regards only the historic centre of Rome and is re-calculated utilizing EBTL data for the whole municipal area. Average expenditure by day-trippers therefore amounts to 111,000 US dollars.

The constraints that we decided to consider are the following:

Hotel beds (HB): capacity of hotel accommodation facilities, measured as the number of beds in hotels.

Non-hotel beds (NHB): capacity of non-hotel accommodation facilities, measured as the number of non-hotel beds. They consist of private accommodation and complementary businesses. The complementary businesses include rented accommodation, camp sites and holiday villages, farm accommodation and country houses, youth hostels, holiday homes, mountain cabins, "other accommodation" not classified elsewhere and since 2002, bed and breakfasts.

Restaurants (R): the capacity of catering facilities, measured as the number of meals per day served in the catering sector (restaurants).

Parking (P): parking capacity, measured as the number of parking spaces.

Public transport capacity $(\mathrm{T})$ : the capacity of local public transport, measured as the number of passengers per day (bus, tram and underground).

Public transport taxi capacity (Ta): the capacity of local public transport, private mobility, measured as the number of taxi passengers per day.

Waste disposal (WD): the capacity of solid urban waste disposal measured in tonnes per day.

Colosseum capacity (CC): the capacity of a tourist attraction. The Colosseum was selected since it is the tourist attraction with the highest number of visitors in Rome; the peak capacity of this attraction was measured as the number of visitors per day. 
To determine the model, maximum capacity and optimum capacity had to be estimated for each constraint. As previously stated, maximum capacity is a physical capacity determined by the maximum value that we can attribute to the considered constraint. Optimum capacity is a part of maximum capacity equal to the maximum value minus the tourist component, assuming that the subset will be used exclusively by residents.

The capacity of hotel and non-hotel accommodation facilities was estimated using ISTAT data from 2006. The number of beds in hotels is equal to 95,367 , a figure that should be considered the maximum capacity of the subset. The optimal capacity was estimated as being equal to an occupation rate of $80 \%$ of this maximum. This quota was used for Venice and it is also applicable to Rome: the underlying hypothesis is that the citizens of Rome have the same personal perceptions about the crowding of hotels as the citizens of Venice. Optimal capacity is therefore 76,294 beds in the hotel sector. The capacity of non-hotel accommodation facilities is equal to 36,642 whereas optimal capacity was calculated, as for Venice, as $50 \%$ of the maximum, equal to 18,321 . We can therefore assume that the occupation rate of non-hotel accommodation is lower than that of hotel accommodation because it includes places that are not used exclusively by visitors.

The catering capacity was estimated using data supplied by the Statistics Office of the Municipality of Rome and ISTAT data. The estimate was arrived at in this way: the total square metre area of the catering facilities in Rome was considered. From interviews with targeted participants, the average number of people per square metre was obtained and an average of two meals per person a day was considered as maximum capacity. Maximum capacity is therefore equal to $1,277,242$ meals per day. Optimal capacity was estimated using ISTAT data based on a multi-purpose survey of families. The ISTAT survey reveals that $7.6 \%$ of residents in Lazio consume a meal in a catering facility; this figure was used to estimate optimal capacity that is consequently equal to $1,180,171.61$ meals daily in restaurants.

Parking capacity was calculated using data sourced from the Agency for Control and Quality of Public Services of the Municipality of Rome. The total number of parking spaces is equal to 94,558. Considering that the residential rate in the historic centre is equal to $17 \%$, this figure was used to calculate an optimal capacityof 78,152 units.

The relative capacity of local public transport, including both public and local companies, was calculated using data provided by the Agency for Control and Quality of Public Services of the Municipality of Rome. For local public transport, the effective number of passengers per kilometre per day on buses, trams and underground was considered. Maximum capacity was therefore calculated as being equal to $12,268,000$ units. This estimate was reduced by $18.7 \%$, the percentage of use by residents: optimal capacity is therefore equal to $9,973,884$ units. Meanwhile, the maximum capacity of private mobility was given by the number of cabs in peak hours, proportioned over the 24 hours, and estimating an average rate of occupation of one person per cab: 1,767,366 day-trippers per day. Assuming an average rate of occupation of one person per cab takes into account the fact that not all taxis are occupied. Considering that the demand for taxi use in the historic centre is equal to $36 \%$ whereas in the suburbs, it is equal to $30 \%$, the $6 \%$ difference is attributed to visitors and the remaining $94 \%$ to residents. Maximum optimal capacity is therefore equal to 106,040 day-trippers per day.

To calculate the maximum capacity of solid urban waste, data from the Agency for Control and Quality of Public Services in the Municipality of Rome and Ama S.p.A. was used. Maximum capacity is 5,012,219 kg per day of solid urban waste equal to the quantity of solid urban waste produced and collected. For optimal capacity, we proceeded as follows: using the Ama S.p.A data, per capita tonnage was calculated for the first district (municipality) considered a tourist one and the other 19 considered non-tourist. The assumption in fact is that the difference in the tonnage per capita of solid urban waste between the first district and the other 19 can be attributed to visitors. A difference of $6 \%$ is attributable to visitors; $94 \%$ was therefore applied to the maximum capacity to refine the production of solid urban waste per resident. Optimal capacity therefore equals $316,220 \mathrm{~kg}$ per day of solid urban waste.

The capacity of the Colosseum was estimated by interviewing targeted participants of the Sovrintendenza speciale per $i$ beni archeologici di Roma (Special Superintendency for the Archaeological Heritage of Rome). The maximum number of visitors was calculated according to the number of seating places and the average length of a visit to the site. With 75,000 seating places and an average length of visit of one hour 20 minutes, and assuming that it is open for eight hours per day, the maximum daily capacity of visitors is equal to 600,000 units. If we assume a share of use by residents of $20 \%$, the optimal capacity of this site is equal to 480,000 visitors per day. The coefficients of the variables TH, TNH and CU, that measure the level of daily use of the $\mathrm{n}$-th service by each category of visitor, were extracted from the Canestrelli-Costa study and correctly re-proportioned for Rome. 
The model of conditioned optimization to solve is therefore summarized as follows in Table 1 with tourists staying in hotels, tourists not staying in hotels and city users, with $x \geq 0,0 \leq \theta \leq 1$.

Table 2 summarizes the sources used in the analysis to measure maximum capacity.

\section{Results}

Linear programming techniques were used to identify the optimal mix of visitors that guarantees maximum daily revenue for the different values of $\theta$.

More specifically, therefore, they can be used to 1) observe what the maximum value of the function is under the constraints, 2) know the trend of the optimum number of visitors by loosening the constraints and comparing the optimal number of visitors and the actual number, 3) understand which are the strongest constraints on which to intervene, and 4) define the utility function for the population that earns a living from tourism and the population that does not and define the optimum value of $\theta$ from the juxtaposition of the two functions. First of all, Table 3 shows the optimal values of tourist hotel accommodation, non-hotel accommodation and daily city users for every level of $\theta$. It also shows the maximum values of the objective function.

Income derived from expenditure of visitors to Rome goes from a minimum of 14,741,440 US dollars per day for $\theta$ equal to zero to a maximum of 44,904,373 US dollars per day for $\theta$ equal to one. It is as well to remember that low values of $\theta$ close to zero indicate that constraints are stronger and that only optimal capacity is considered in the model. Values of $\theta$ closer to one, on the other hand, express maximum relaxation of the constraints, and indicate that the capacity of the subset is the maximum capacity. As already noted in the table, the model does not admit non-hotel tourist accommodation and city users for values of $\theta$ between zero and 0.1 whereas when $\theta$ is equal to 0.2 , it allows non-hotel tourist accommodation but does not allow city users.

Figure 1 shows the ongoing trend of visitors when $\theta$ varies and shows the most active constraints. An active constraint is a tight constraint that has not been violated (the model does not allow it), but on which the function values press, i.e., they are on the border. These constraints are therefore more significant to observe and are those that require economic policy intervention.

As can be seen in Figure 1, for values of $\theta$ between zero and 0.1, the active constraint, i.e., the tightest constraint, for which the values of visitors are on the border, are parking spaces. For values of $\theta$ between 0.1 and 0.2 , the constraints are parking spaces and the number of hotel beds; for values of $\theta$ between 0.2 and 0.3 , they include the number of beds in non-hotel accommodation and in the complementary sectors as well as parking spaces and the number of hotel beds. These constraints remain active for all the values of $\theta$ and are therefore those requiring intervention. Moreover, the figure shows the trend of different types of visitors. Hotel tourists and non-hotel tourists have the same trend as the variation of $\theta$, with the difference that non-hotel tourists are equal to zero when $\theta$ is less than 0.2 . For low values of $\theta$, both increase more quickly, then slow down and continue to increase more slowly for values of $\theta$ higher than 0.2 , for the first and 0.3 for the second. Daily city users are equal to 0 for values of $\theta$ lower than 0.3 and then increase at a constant rate, always remaining lower than hotel tourists and lower than non-hotel tourists until $\theta$ is equal to around 0.55 , beyond which they are higher. This phenomenon can be attributed to the fact that both hotel beds and non-hotel beds are tight constraints and therefore the number of hotel and non-hotel tourists increases, but less than the potential increase in city users who are not affected by the capacity of hotel and complementary accommodation.

The model has enabled us to estimate the objective functions of the population that earns a living from tourism and the population that does not. The importance of these functions is demonstrated in various studies (Butler R.W., 1980, Davis D. et al. 1988, Bimonte S. and Punzo L.F. 2007). While the interests of the first group are represented in the objective function that approximates the net benefits obtainable from the tourist industry to an increase in the number of visitors, the interests of the second group are represented by the objective function that approximates the constraints applied to the carrying capacity of the subsystems; these constraints represent the costs incurred by this group. To estimate the utility functions, the model defines two functions:

the first:

$$
\mu_{c}(\theta)=1-\theta
$$

the second:

$$
\begin{aligned}
\mu_{\mathrm{f}}\left(\mathrm{Z}_{0}(\theta),(\theta)\right) & =0 & & \text { if } \mathrm{Z}_{0}(\theta)<\mathrm{b}_{0}-\mathrm{p}_{0} \\
& =1-\mathrm{t} & & \text { if } \mathrm{Z}_{0}(\theta)=\mathrm{b}_{0}-\mathrm{tp}_{0} \\
& =1 & & \text { if } \mathrm{Z}_{0}(\theta)>\mathrm{b}_{0}
\end{aligned}
$$


where $Z_{0}$ is a fuzzy set (Zadeh, 1968); $b_{0}$ is the maximum aspiration level of the target function and $\mathrm{p}_{0}$ is the minimum acceptable level of the target function defined a priori. For every possible value of $\theta$, an optimal solution of the visitor mix is obtained, if it exists, that maximizes both the target functions of the two population groups. Let us assume that $b_{0}$ is equal to $35,737,663$, that is, equal to the value of maximum revenue, with $\theta$ equal to 1 . At the same time, $p_{0}$ is assumed to be equal to $24,627,636$, that is, the first value of the maximized function that admits hotel tourists, non-hotel tourists and city users. Figure 2 shows the results of the analysis.

As we can see from the figure, when $\theta$ increases, the utility function $\left(\mu_{\mathrm{c}}\right)$ of the population that does not depend on tourism decreases linearly from zero to one whereas that of the population that depends on tourism $\left(\mu_{\mathrm{f}}\right)$ increases at a higher speed for values of $\theta$ between zero and 0.2 and then increases at lower rates.

The optimal value of $\theta$ resulting from where the two curves meet is equal to 0.4. For this value of $\theta$, the optimal solution estimates 83,923 hotel tourists, 25,649 non-hotel tourists, 15,344 city users and a daily revenue of $32,938,874$ US dollars, more than the actual revenue and equal to $13,567,065$ US dollars per day (data refers to 2005, Rome Economic Report 2006-2007, page 324). From the data sourced from EBTL, the actual hotel tourists (daily presence) are equal to 58,907 and non-hotel tourists (daily presence) are equal to 18,280 . Actual city users were estimated using Ama data. Ama estimates an equivalent population in Rome of around 3,200,000 people. Since there are approximately 2,800,000 residents, the number of commuters and tourists is estimated to be about 400,000 units. The number of hotel and non-hotel tourists was then subtracted from this value and the number of daily city users is thus equal to 322,812 units. The linear programming technique allowed us to verify that while the optimal number of hotel tourists and non-hotel tourists is higher than the actual number, the number of city users is decisively lower.

\section{Conclusion}

The linear programming technique used in the literature in several studies (see Van de Panne C., 1975) allowed us to quantify the carrying capacity of the city of Rome by taking into account the different load capacities of its subsets and the different objective functions of the people dependent or not dependent on tourism. With an optimal value of parameter $\theta$ equal to 0.4 , a value that allows maximization of the target functions of the two social groups, the optimal number of hotel and non-hotel tourists results in a number that is higher than the actual one whereas the number of the city users is lower; moreover, optimal daily revenue is higher than the actual figure, as shown in Table 4.

Table 4 shows that it is important to bear in mind that the cost-benefit balance of tourism in Rome currently records a significant loss of revenue. Optimal revenue corresponding to the maximum satisfaction of the people who depend on tourism and those who do not, equals around 12 billion US dollars per annum and is higher than the actual figure of around five billion US dollars per annum, indicating a loss in social gain of around seven billion US dollars per annum.

Finally, analysis then demonstrated the need to control or intervene on some of the considered subsystems, subsystems that may obstruct the economic growth of the city: these subsystems are the number of parking spaces and hotel and non-hotel beds.

\section{References}

Archer, B. (1996). Economic impact analysis. Annals of tourism research, 23(3), 704-707. http://dx.doi.org/10.1 016/0160-7383(95)00097-6

Ashworth, G. (1994). Heritage, tourism and sustainability: a Canadian case. Paper presented at the expert meeting on "Sustainability in tourism and leisure. Tilburg.

Ashworth, G. J., \& Tunbridge, J. E. (1990). The tourist-historic city. London, Belhaven.

Bimonte, S., \& Punzo, L. F. (2007). The evolutionary game between tourist and resident population and tourist carrying capacity. International Journal of Technology and Globalisation, 3(1), 73-87. http://dx.doi.org/10.1504/ IJTG.2007.012361

Berg. L., van der Borg, J., \& Van der Meer, J. (1995). Urban Tourism: Performance and strategies in eight European cities, Avebury, Aldershot.

Butler, R. W. (1980). The concept of a tourist area cycle of evolution: implications for the management of resources. Canadian Geographer, 24(1), 5-12. http://dx.doi.org/10.1111/j.1541-0064.1980.tb00970.x

Canestrelli, E., \& Costa, P. (1991). Tourist carrying capacity. A fuzzy approach, Annals of tourism research, 18, 295-311. http://dx.doi.org/10.1016/0160-7383(91)90010-9 
Cazes, G., \& Potier, F. (1996). Le tourisme urbain. Paris. Presses Universitaires de France.

Costa, P., \& Tan van der, B. (1991). The Impact of Tourism in Cities of Art. Paper presented at UNESCO-ROSTE workshop. Art Cities and Visitors Flow. The Management of Tourism in Cities of Art, 10, 45-57.

Davis, D., Allen, J., \& Cosenza, M. R. (1988). Segmenting local residents by their attitudes, interests, and options toward tourism. Journal of Travel Research, 27(2), 2-8. http://dx.doi.org/10.1177/004728758802700201

Debbage, K. G. (1990). Oligopoly and the resort cycle in the Bahamas. Annals of Tourism Research, 17, 513-527. http://dx.doi.org/10.1016/0160-7383(90)90024-L

Deyak, T., \& Smith, V. K. (1978). Congestion and participation in outdoor recreation: a household production approach. Journal of Environmental Economics and Management, 5, 63-80. http://dx.doi.org/10.1016/0095-069 6(78)90005-0

Doxey, G. V. (1975). A causation theory of visitor-resident irritants: methodology and research inferences. Proceedings of the Travel Research Association, 6th annual, 195-198.

Duffield, B. S. (1982). Tourism: the measurement of economic and social impact. Tourism Management, 25(3), 248-255. http://dx.doi.org/10.1016/0261-5177

Dwyer, L., Forsyth, P., \& Spurr, R. (2004). Evaluating tourism's economic effects: new and old approaches, Tourism Management, 25(3), 307-317. http://dx.doi.org/10.1016/S0261-5177

Fischer, A. C., \& Krutilla, J. V. (1972). Determination of optimal capacity of resourced-based recreation facilities. Natural Resources Journal, 12, 417-444.

Getz, D. (1994). Residents' attitudes towards tourism. Tourism Management, 15, 247-258. http://dx.doi.org/10.1 016/0261-5177(94)90041-8

Gilbert, D., \& Clark, M. (1997). An exploratory examination of urban tourism impact with reference to residents attitudes, in the cities of Canterbury and Guildford. Cities, 14(6), 343-352. http://dx.doi.org/10.1016/S0264-2751 (97)00025-5

Glasson, J., Kerry, G., \& Brian, G. (1995). Towards Visitor Impact Management. Aldershot: Avebury.

Guitiérrez-i-Puigarnau, E., \& van Ommeren, J. N. (2010). Labour supply and commuting. Journal of Urban Economics, 68(1), 82-89. http://dx.doi.org/10.1016/j.jue.2010.03.003

Holder, J. S. (1991). In Managing tourism, S. Medlik (ed.), Pattern and impact of tourism on the environment of the Caribbean (pp. 278-284). Oxford: Butterworth-Heinemann.

Joardar, S. D. (1988). Carrying capacities and standards as bases towards urban infrastructure planning in India: a case of urban water supply and sanitation. Habit Int, 22(3), 327 -337. http://dx.doi.org/10.1016/S0197-3975(98) 00002-2

Knowles, T., \& Curtis, S. (1999). The market viability of European mass tourist destinations: a post-stagnation lifecycle analysis, International Journal of Tourism Research, 1, 87-96. http://dx.doi.org/10.1002/(SICI)1522-19 70(199903/04)1:2<87::AID-JTR135>3.0.CO;2-6

Christopher, M. (1993). Urban Tourism. London: Mansell.

Martin, B. S., \& Uysal, M. (1990). An examination of the relationship between carrying capacity and the tourism lifecycle: management and policy implications, Journal of Environmental Management, 31, 327-333. http://dx.doi.org/10.1016/S0301-4797(05)80061-1

Mbaiwa, J. E. (2005). Enclave tourism and its socio-economic impacts in the Okavango Delta, Botswana, Tourism Management, 26(2), 157-172. http://dx.doi.org/10.1016/j.tourman.2003.11.005

Prideaux, B. (2000). The Resort Development Spectrum: A New Approach to Modeling Resort Development. Tourism Management, (21), 225-240. http://dx.doi.org/10.1016/S0261-5177(99)00055-2

Prud'homme, R. (1986). Le tourisme et le développement de Venise. Moteur ou frein?. OCDE, IUP, Université de Paris XII, Créteil, mimeo.

Rapporto economia romana 2006-2007. (2008). pp. 324-325.

Rappaport, J. (2004) .Why are population flows so persistent?. Journal of Urban Economics, 56(3), 554-580. http://dx.doi.org/10.1016/j.jue.2004.07.002 
Snaith, T., \& Haley, A. (1999). Residents' opinions of tourism development in the historic city of York, England. Tourism Management, 20, 595-603. http://dx.doi.org/10.1016/S0261-5177(99)00030-8

Soleimani-damaneh, M., \& Jahanshahloo, G. R. (2007). Optimal and strongly optimal solutions for linear programming models with variable parameters, Applied Mathematics Letter, 20(10), 1052-1056. http://dx.doi.or g/10.1016/j.aml.2006.10.004

Terence, W. J. (1978). Labour supply and commuting time: an empirical study. Journal of Econometrics, 8(2), 215-226. http://dx.doi.org/10.1016/0304-4076(78)90030-1

Van de Panne, C. (1975). Methods for Linear and Quadratic Programming. Amsterdam, North Holland: Elsevier.

Van der Borg, J. (1991). Tourism and urban development. Amsterdam, Thesis publishers.

Van der Borg, J., Costa, P., \& Gotti, G. (1996). Tourism in European heritage cities. Annals of Tourism Research, 23(2), 306-321. http://dx.doi.org/10.1016/0160-7383(95)00065-8

Voith, R. (1991). The long-run elasticity of demand for commuter rail transportation. Journal of Urban Economics, 30(3), 360-372. http://dx.doi.org/10.1016/0094-1190(91)90055-C

Zadeh, L. A. (1968). Fuzzy algorithms. Information and Control, 5, 94-102. http://dx.doi.org/10.1016/S0019-99 58(68)90211-8

Table 1. Constrained optimization model to be solved

\begin{tabular}{lrc}
\hline Constraints: & \multicolumn{3}{l}{} \\
\hline $\mathrm{HB}$ & $1.00 \cdot \mathrm{TH}+0.00 \cdot \mathrm{TNH}+0.00 \cdot \mathrm{CU}=$ & $72,293.60+\theta \cdot 19,073.40$ \\
$\mathrm{NHB}$ & $0.00 \cdot \mathrm{TH}+1.00 \cdot \mathrm{TNH}+0.00 \cdot \mathrm{CU}=$ & $18,321.00+\theta \cdot 18,321.00$ \\
$\mathrm{R}$ & $1.00 \cdot \mathrm{TH}+0.75 \cdot \mathrm{TNH}+0.50 \cdot \mathrm{CU}=$ & $1,180,171.61+\theta \cdot 97,070.39$ \\
$\mathrm{P}$ & $0.33 \cdot \mathrm{TH}+0.33 \cdot \mathrm{TNH}+0.75 \cdot \mathrm{CU}=$ & $16,405.81+\theta \cdot 78,152.19$ \\
$\mathrm{~T}$ & $3.00 \cdot \mathrm{TH}+2.00 \cdot \mathrm{TNH}+1.50 \cdot \mathrm{CU}=$ & $2,294,116.00+\theta \cdot 9,973,884.00$ \\
$\mathrm{TA}$ & $0.20 \cdot \mathrm{TH}+0.20 \cdot \mathrm{TNH}+0.10 \cdot \mathrm{CU}=$ & $1,661,295.84+\theta \cdot 106,040.16$ \\
$\mathrm{WD}$ & $2.30 \cdot \mathrm{TH}+2.00 \cdot \mathrm{TNH}+1.50 \cdot \mathrm{CU}=$ & $4,695,999.31+\theta \cdot 767,3030.74$ \\
$\mathrm{CC}$ & $0.47 \cdot \mathrm{TH}+0.30 \cdot \mathrm{TNH}+0.70 \cdot \mathrm{CU}=$ & $480,00.00+\theta \cdot 120,000.00$ \\
\hline
\end{tabular}

Table 2. Data/Data sources used (2006)

\begin{tabular}{lcc}
\hline Constraints: & Data & Data Sources \\
\hline $\mathrm{HB}\left(\mathrm{n}^{\circ}\right)$ & 95,367 & ISTAT \\
$\mathrm{NHB}\left(\mathrm{n}^{\circ}\right)$ & 36,642 & ISTAT \\
$\mathrm{R}\left(\mathrm{n}^{\circ}\right)$ & $1,277,242$ & Municipality of Rome (statistics office) and ISTAT. \\
$\mathrm{P}\left(\mathrm{n}^{\circ}\right)$ & 94,558 & Municipality of Rome (Control and Quality Agency). \\
$\mathrm{T}\left(\mathrm{n}^{\circ}\right)$ & $12,268,000$ & Municipality of Rome (Control and Quality Agency). \\
$\mathrm{TA}\left(\mathrm{n}^{\circ}\right)$ & $1,767,336$ & Municipality of Rome (Control and Quality Agency). \\
$\mathrm{WD}(\mathrm{Kg})$ & $5,012,219$ & Ama S.p.A and Municipality of Rome. \\
$\mathrm{CC}\left(\mathrm{n}^{\circ}\right)$ & 600 & Special Superintendency for the Archeological Heritage of Rome. \\
$C_{1}(\$)$ & 297 & Ente bilaterale turismo locale (EBTL) \\
$C_{2}(\$)$ & 247 & Ente bilaterale turismo locale (EBTL) \\
$C_{3}(\$)$ & 111 & Ente bilaterale turismo locale (EBTL) \\
\hline
\end{tabular}


Table 3. Optimal solution per level of parameter

\begin{tabular}{|l|c|c|c|c|}
\hline$\Theta$ & $\mathrm{TH} / 1000$ & $\mathrm{TNH} / 1000$ & $\mathrm{CU} / 1000$ & $\mathrm{Z}$ \\
\hline $0 \%$ & 49.7 & - & - & $14,741.440$ \\
\hline $10 \%$ & 73.4 & - & - & $21,763.804$ \\
\hline $20 \%$ & 80.1 & 17.0 & - & $27,954.515$ \\
\hline $30 \%$ & 82.0 & 23.8 & 6.6 & $30,944.624$ \\
\hline $40 \%$ & 83.9 & 25.6 & 15.3 & $32,938.874$ \\
\hline $50 \%$ & 85.8 & 27.5 & 24.1 & $34,993.123$ \\
\hline $60 \%$ & 87.7 & 29.3 & 32.9 & $36,927.374$ \\
\hline $70 \%$ & 89.6 & 31.1 & 41.7 & $38,921.624$ \\
\hline $80 \%$ & 91.6 & 33.0 & 50.4 & $40,915.873$ \\
\hline $90 \%$ & 93.5 & 34.8 & 59.2 & $42,910.123$ \\
\hline $100 \%$ & 95.4 & 36.6 & 68.0 & $44,904.373$ \\
\hline
\end{tabular}

Table 4. Findings. Annual Values

\begin{tabular}{|l|c|c|c|}
\hline Variable & Optimal - Annual & Actual-Annual & Optimal-Actual \\
\hline TH (number) & $30,631,880$ & $21,501,213$ & $9,130,667$ \\
\hline TNH (number) & $9,362,031$ & $6,672,379$ & $2,689,652$ \\
\hline CU (number) & $5,600,560$ & $117,826,408$ & $-112,225,848$ \\
\hline Income (US dollars) & $12,022,688,957$ & $4,951,978,674$ & $7,070,710,283$ \\
\hline
\end{tabular}

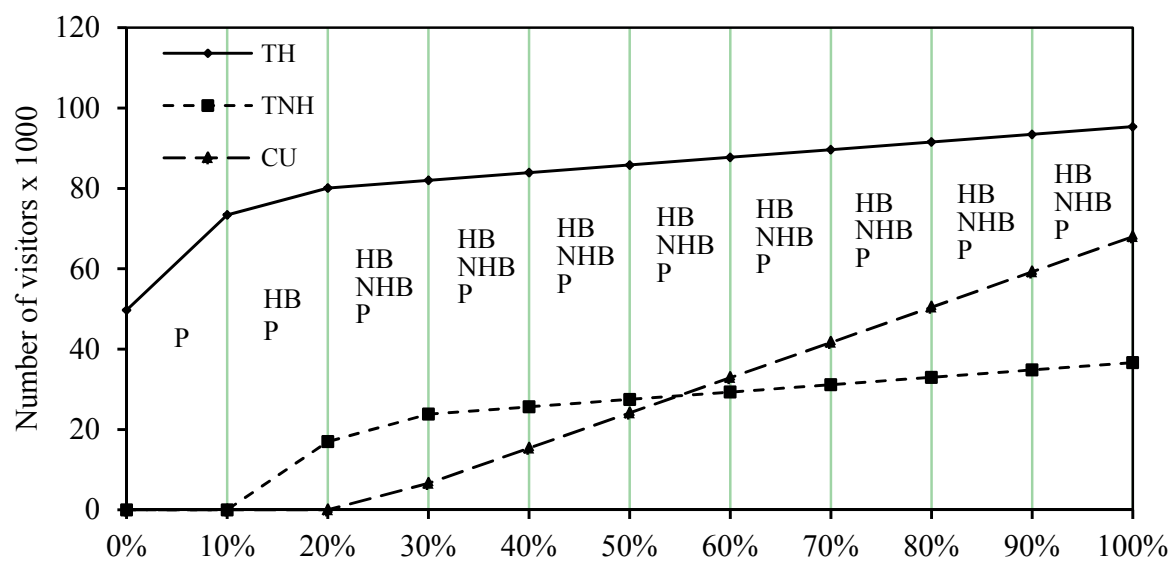

Degree of conditioning factor breach

Figure 1. Optimal mix of visitors

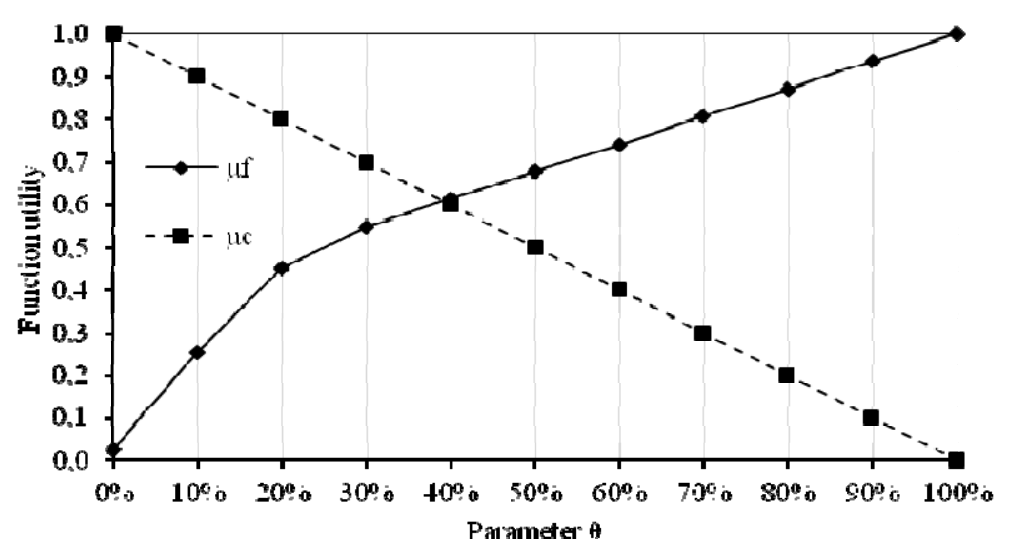

Figure 2. Results of analysis (Optimal level of parameter) 